\title{
Branching pattern variations of the celiac trunk and superior mesenteric artery in a 72-year-old white female cadaver
}

\author{
Guinevere Granite ${ }^{1}$, Keiko Meshida ${ }^{2}$, Gary Wind ${ }^{1}$
}

Granite G, Meshida K, Wind G. Branching pattern variations of the celiac trunk and superior mesenteric artery in a 72-yearold white female cadaver. Int J Anat Var. 2019;12(4): 55-59.

Variations in the branching patterns of the celiac trunk and superior mesenteric artery occur frequently. Detailed knowledge of anatomical variations of the abdominal arterial supply is important for the outcome of abdominal organ surgical intervention, abdominal aortic aneurysm repairs, liver resections, oncologic evaluations and chemoembolization of hepatic tumors. Familiarity with such variations is equally important for instructors teaching anatomy to students in the various medical disciplines. Case studies highlighting such vascular variations provide anatomical instructors and surgeons with accurate information on the types and prevalence of such alterations. This article highlights branching pattern variations of the celiac trunk and superior mesenteric artery involving the left and right hepatic arteries of a 72-year-old White Female cadaver. The left hepatic artery was one of the branches of the celiac trunk instead of the common hepatic artery, and the right hepatic artery was a branch of the superior mesenteric artery.

Key Words: Celiac trunk variations, Superior mesenteric variations, Abdominal aorta variations, Arterial branching variations, Replaced or aberrant left hepatic artery, Replaced or aberrant right hepatic artery

\section{INTRODUCTION}

$\mathrm{V}$ ariations in the branching patterns of the celiac trunk and superior mesenteric artery occur frequently and are usually asymptomatic [1-8]. Knowledge of variations and preoperative study of the vascular patterning of the abdominal viscera is important to avoid iatrogenic complications during intraabdominal surgical and diagnostic procedures [1,3-35]. Reports of case studies on the types and prevalence of such variations, thus, are key to providing anatomical instructors and surgeons with accurate information. This article highlights branching pattern variations of the celiac trunk (CT) and superior mesenteric artery (SMA).

During anatomical dissection of 82 cadavers in the 2017-2019 undergraduate medical and graduate nursing anatomy courses at the Uniformed Services University of the Health Sciences, we found one example of CT and SMA branching pattern variations involving the left hepatic artery (LHA), right hepatic artery (RHA), and absence of a common hepatic artery (CHA) (1.2\% of the studied population) (Figure 1). These variations presented in a 72-yearold White Female cadaver, provided by the Maryland State Anatomy Board.

\section{CASE DESCRIPTION}

The branching pattern variations observed in this 72-year-old White Female (listed cause of death of respiratory failure and intracranial hemorrhage) were as follows. The CT had the branches of the left gastric artery (LGA), splenic artery (SA), and the LHA. There was no CHA. The SMA had the following branches: the right hepatic artery (RHA), inferior pancreatic duodenal artery (IPDA), middle colic artery (MCA), right colic artery (RCA), ileocolic artery (ICoA), and the ileal-jejunal arteries (I-JAs) (Figures 1-4). The RHA had the following branches: the right gastric artery (RGA), gastro duodenal artery (GDA), and the cystic artery (CA). An arterial branch contributing to the

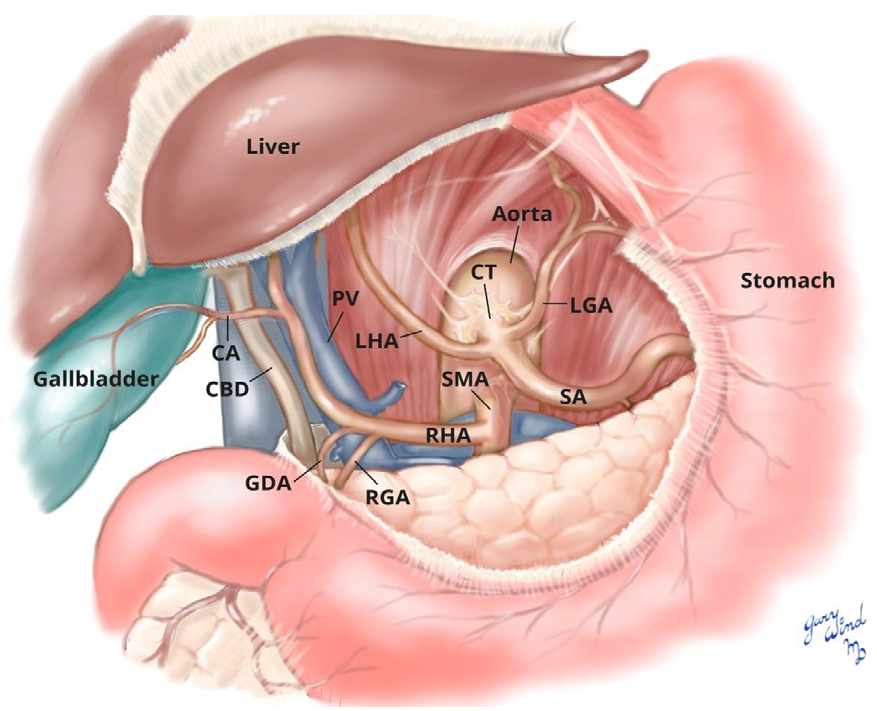

Figure 1) Illustrative schematic of the abdominal vessels and associated structures highlighting the branching of the Celiac Trunk and Superior Mesenteric Artery of the featured case: CT: Celiac Trunk; SMA: Superior Mesenteric Artery; IMA: Inferior Mesenteric Artery; CBD: Common Bile Duct; PV: Portal Vein; LHA: Left Hepatic Artery; RHA: Right Hepatic Artery; SMA: Superior Mesenteric Artery; SV: Splenic Vein; CT: Celiac Trunk; LC: Left Crus of the Diaphragm; LGA: Left Gastric Artery; SA: Splenic Artery.

right gastroepiploic artery (RGEA1 and RGEA2) arose from the RGA and the GDA. The GDA also had a branch for the anterior superior pancreatic duodenal artery (ASPDA) (Figures 3 and 4). The splenic vein (SV) joined the superior mesenteric vein (SMV) to form the PV.

${ }^{1}$ Department of Surgery, Uniformed Services University of the Health Sciences, Bethesda, MD, USA; ${ }^{2}$ Department of Anatomy, College of Medicine, Howard University, Washington, DC, USA

Correspondence: Dr. Guinevere Granite, Department of Surgery, Uniformed Services University of the Health Sciences, Bethesda, MD, USA. Telephone +301-295-1500; E-mail: guinevere.granite@usuhs.edu

Received: Aug 10, 2019, Accepted: Nov 12, 2019, Published: Nov 19, 2019 


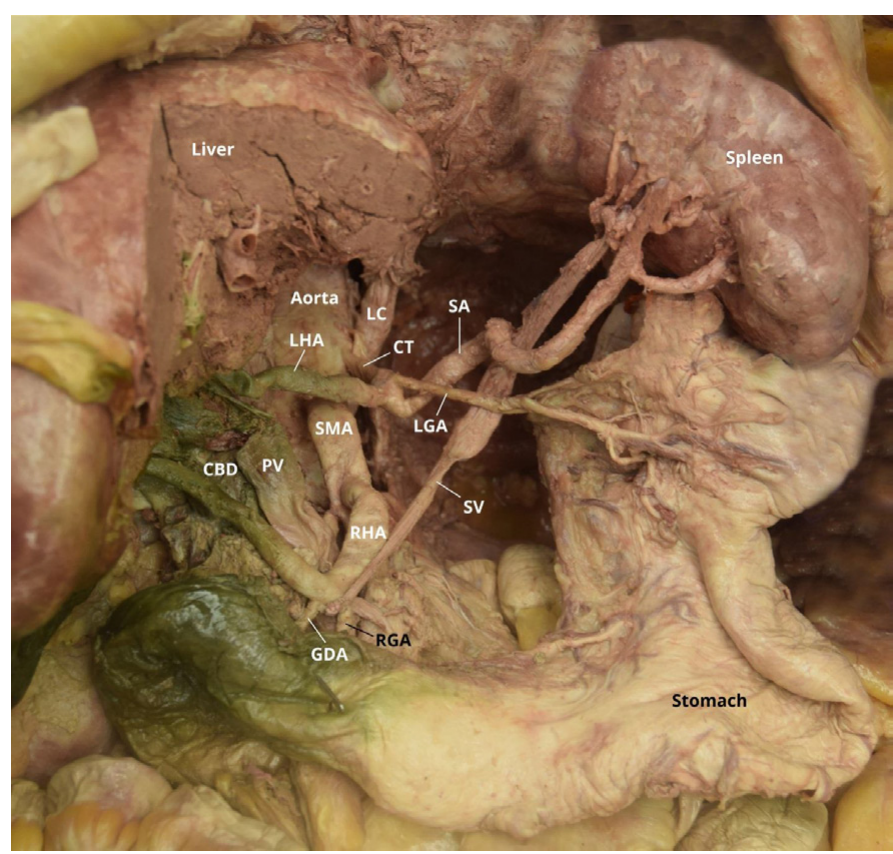

Figure 2) Facilitated display of the upper abdominal aorta of the featured case: CBD: Common Bile Duct; PV: Portal Vein; LHA: Left Hepatic Artery; RHA: Right Hepatic Artery; SMA: Superior Mesenteric Artery; SV: Splenic Vein; CT: Celiac Trunk; LC: Left Crus of the Diaphragm; LGA: Left Gastric Artery; SA: Splenic Artery.

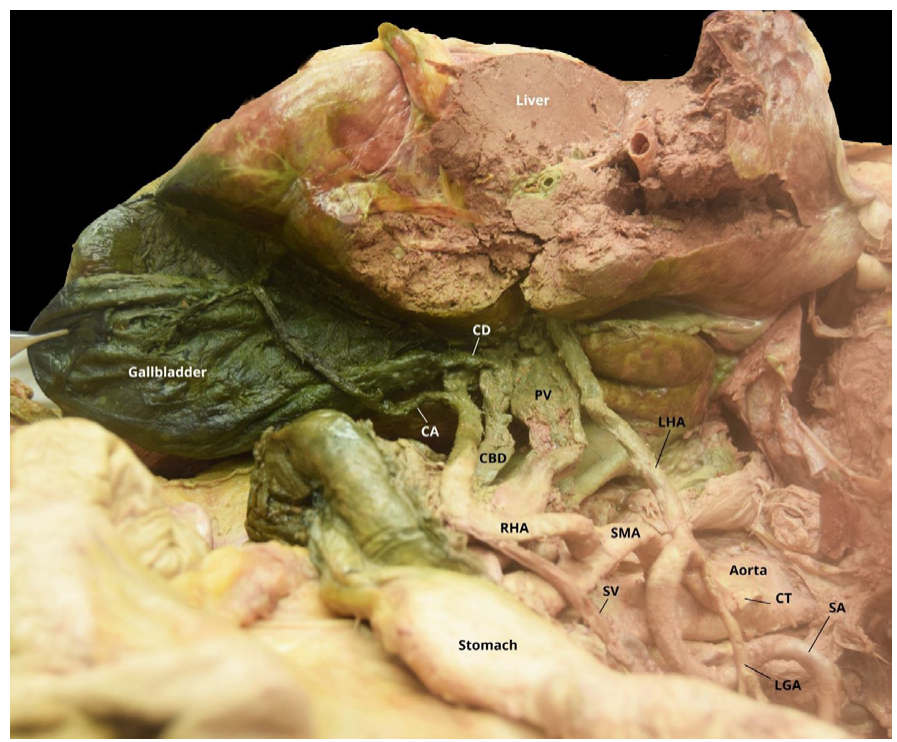

Figure 3) Facilitated display of the upper abdominal aorta and the association of its branches to the liver and gallbladder of the featured case: CAB1: Cystic Artery Branch 1; CAB2: Cystic Artery Branch 2; CA: Cystic Artery; RHA: Right Hepatic Artery; CD: Cystic Duct; CBD: Common Bile Duct; PV: Portal Vein; LHA: Left Hepatic Artery; SMA: Superior Mesenteric Artery; SV: Splenic Vein; CT: Celiac Trunk; LGA: Left Gastric Artery; SA: Splenic Artery.

\section{DISCUSSION}

\section{Embryonic development}

Variation in the number and branching pattern of the abdominal vasculature may correlate with embryonic development [10]. The arteries of the gut begin as ventral segmental branches of the paired dorsal aortae. These ventral branches are initially paired and distributed to the developing gut and its derivatives. During the fourth week of embryonic life, the dorsal aortae fuse as the gut tube lengthens and rotates, accompanied by migration of the associated viscera. As they fuse, so do the paired ventral branches, forming unpaired segmental arteries. These segmental arteries supply the dorsal gut mesentery and divide into ascending and descending branches. These branches form a continuous longitudinal anastomotic channel along the

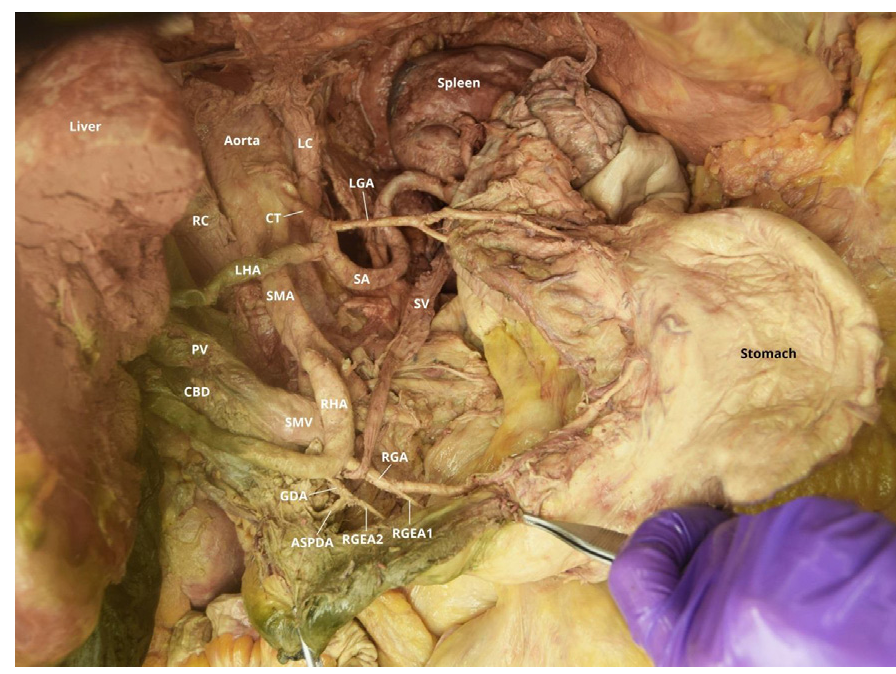

Figure 4) Facilitated display of the upper abdominal aorta and the association of its branches to the stomach and pancreas of the featured case: LC: Left Crus of the Diaphragm; RC: Right Crus of the Diaphragm; CT: Celiac Trunk; LGA: Left Gastric Artery; LHA: Left Hepatic Artery; SMA: Superior Mesenteric Artery; SA: Splenic Artery; SV: Splenic Vein; PV: Portal Vein; CBD: Common Bile Duct; PHAL: Proper Hepatic Artery; SMV: Superior Mesenteric Vein; RHA: Right Hepatic Artery; RGA: Right Gastric Artery; GDA: Gastroduodenal Artery; ASPDA: Anterior Superior Pancreaticoduodenal Artery; RGEA1: Right Gastroepiploic Artery 1; RGEA2: Right Gastroepiploic Artery 2.

dorsal and ventral aspects of the developing gut. They provide arterial supply to the primitive digestive tube. Over time, several ventral branches regress or fuse. This reduces the number of the main abdominal aortic artery branches to the three unpaired midline vessels: the CT (the $10^{\text {th }}$ segmental artery), the SMA (the $13^{\text {th }}$ segmental artery), and the IMA (the $21^{\text {st }}$ or $22^{\text {nd }}$ segmental artery). Thus, alterations both in fusion and regression result in branching variation of the three major abdominal aortic branches. In addition, because their embryonic origins are closely related, persistence of interconnections or overlapping of the territories of the CT, SMA, and IMA are common $[3,4,8$ $14,18,30,31,34,36-38]$.

The persistence of the ventral longitudinal anastomoses connecting the ventral segmental arteries destined to become the CT, the SMA, or the IMA reasonably explains the occurrence of the LHA as a branch of the CT and RHA as a branch of the SMA $[1,3,4,9]$. Other factors that may contribute to abdominal vascular variations include the midgut rotation, physiological herniation, migration of the spleen leftward, and hemodynamic changes in the abdominal viscera [9].

\section{Celiac trunk variations}

Typically, in human anatomy, the abdominal aorta gives rise to three ventral branches: the CT, SMA, and the inferior mesenteric artery (IMA). The CT normally originates as the first ventral branch, supplying the foregut (i.e. the stomach, spleen, pancreas, liver, and part of the duodenum) $[3,4,7,9,10,12,14,16,18,24-26,33,34,39-42]$. Venous drainage of the foregut is principally through the portal vein (PV).

The CT, also known as the coelic artery, coelic axis or truncus coeliakus, usually arises just below the aortic hiatus at the level of the intervertebral disc between the T12 and L1 vertebrae. The CT is normally 1.5 to 2.3 $\mathrm{cm}$ long, and its trunk traverses horizontally forward, trifurcating into the LGA, CHA, and SA $(55-100 \%$ of the population) $[1,3,4,6-10,12,14,16,18,23$ 26,28,29,33,34,39-44]. This trifurcation was first described by Haller in 1756 as tripus Halleri $[7,8,18,21,22,24,28,30,35,45,46]$. The origin of the CT from the abdominal aorta, however, can vary. Kao et al. (1992) found that the CT emerged at the T2 level in 48\% of the celiac angiograms they studied [45,47]. Yang et al. (2011) found it emerging at the intervertebral space between T11 and $\mathrm{T} 12$ in $6.55 \%$ of their cases $[7,40,45]$. A high CT origin can predispose one to impingement by the median arcuate ligament and cause celiac axis compression syndrome (CACS). CACS presents with postprandial epigastric pain, nausea, and vomiting [7]. Nayak et al. (2013) referenced a case where the CT arose opposite the L2 vertebra [48]. Sahni et al. (2016) also found varying locations of the CT origin: at the level of T12 in $62.5 \%$ of 50 cases, between $\mathrm{T} 12$ and $\mathrm{L} 1$ in $30 \%$ of cases, at the level of $\mathrm{L} 1$ in $2.5 \%$ of cases, and at the level of the intervertebral disk between L1 and L2 in 5\% of cases 
[45]. Pinal-Garcia et al. (2018) found the origin of CT to range from the T10 vertebral body to the $\mathrm{L} 1$ vertebral body [28].

In addition to an extensive literature on origin variation, there is a substantial literature pertaining to branching pattern variation of the CT. To identify a vessel as a CT, two of the three major branches must be present (hepatosplenic, gastrosplenic, gastrohepatic) with the missing branch originating elsewhere. Various authors have classified such CT variations: Lipshutz (1917), Adachi (1928), Morita (1935), Michels (1951), Uflacker (1997), Babu E and Khrab (2013), Sureka et al. (2013), Panagouli et al. (2013) $[2,5,6,8,18,21,-24,26,28,30,35,43,49-53]$. Variations in the CT branching pattern can involve from two to six different branches [45]. These branch variations include: $\operatorname{GDA}(3.61 \%, 3.3 \%, 0.2 \%, 1.7 \%$ of cases $)[20,30,49]$ inferior phrenic arteries $(13 \%, 28.2 \%, 30-51 \%)$ [32] left or right middle suprarenal artery (3.3\%) [54] left superior suprarenal artery [3] left middle suprarenal artery [3] dorsal pancreatic artery [9] RHA [4] accessory hepatic artery and retroportal artery [55] MCA (1.2-4.8\%) [42]. Generally, these branch variations manifest in place of or in addition to the usual branches of LGA, CHA, and SA, and are known as replaced (aberrant) or accessory [3]. They may be the result of either portions of the longitudinal channels persisting or disappearance of parts that are normally present $[3,6]$. The CT branch variation highlighted in this article replaced one of the usual branches: the LHA instead of the CHA. Two to twenty percent of individuals exhibit aberrant LHA [1,19,53]. Makisalo et al. (1993) and Raviprasanna and Kulkarni (2018) reported one case in each of their cohorts that had an accessory LHA arising from the CT [45,56,57]. In its absence $(0.38-1.4 \%)$, branches of the CT may arise from the aorta $[4,7,8,27,28,34,35,38,42-44,58]$.

\section{Superior mesenteric artery variations}

Typically, the SMA originates as the second ventral branch of the abdominal aorta, supplying the midgut. Specifically, this vessel supplies part of the duodenum, a portion of the head and the pancreatic body, the entire small intestines, and the large intestine up to the right two-thirds of the transverse colon. Its normal branching pattern from its right concave side is as follows: the IPDA, MCA, RCA and the ICoA. Several I-JAs branch from its left convex side $[25,45]$. Venous drainage for the midgut is principally through the superior mesenteric vein (SMV) into the PV.

Variations in SMA origin are much more diverse than described in standard anatomy textbooks [45]. Its traditional origin is from the abdominal aorta at the level opposite the lower third of L1 vertebra. SMA origin, however, can vary from the lower border of T12 to the intervertebral disk between L2 and L3 vertebrae [50]. Prakash et al. (2011) reported an atypical level of origin in $24 \%$ of the cases they studied [29]. Matusz et al. (2013) reported a unique case involving a CT and SMA origin from the thoracic part of the aorta, approximately $21 \mathrm{~mm}$ and $9 \mathrm{~mm}$ above the aortic hiatus [58].

In addition to arising from various locations along the aorta, the SMA can also fuse with or arise with components of the CT. When the SMA fuses with the CT at its origin, it forms a celiacomesenteric trunk (CMT), usually occurring in $1-2 \%$ of cases [1,26]. Tsukamoto (1929), however, found an extraordinarily high percentage (11\%) in the cohort he studied [59]. SMA can also arise jointly with one or any two components of the CT. When it shares a common trunk of origin with the SA, it is known as a splenomesenteric trunk and occurs in $0.16-1 \%$ of cases [29]. A hepatosplenomesenteric trunk, occurring in $0.68-1.7 \%$ of cases, involves the SMA fusing with both the splenic and hepatic arteries [60]. Another variation is a common origin stem shared by the LGA, SA, and SMA [45]. Nonent et al. (2001) coined the term celiaco-bimesenteric trunk to describe the extremely unusual variation in which the SMA originated with the CT and IMA from the aorta at the level of L2 vertebra [61]. An additional rare variation occurs when the SMA joins as a common trunk with the IMA from the aorta (less than $0.1 \%$ ). This joint origin of the SMA and IMA usually arises from the abdominal aorta at the level where the normal SMA would arise [61-63]. Maleux et al. (2010), however, reported the common trunk of SMA and IMA can arise at the level of L5 [64]. In such a case, the IMA usually emerges as the first branch of the SMA. Conversely, Gwyn and Skilton (1966) reported the same variation, but the IMA arose as the second colic branch from the SMA [62]. Others have reported the IMA and CHA stemming from the SMA, forming a common hepatomesenteric trunk [63]. Power (1850) found the SMA can also arise from the internal iliac artery [65].

Similar to origin variation, the SMA can have a variety of branches. The traditional SMA branching pattern, in which all of the branches arise separately from the SMA, occurred in only $22 \%$ of cadavers assessed by Nelson et al. (1988) in 28.7\% assessed by Sonneland et al. (1958), and in onethird of 200 cadavers assessed by Michels et al. (1965) $[1,15,45,66]$. Branching variation associated with the SMA can include normal CT branches and their sub-branches. Possible branching variations include the RGA (12.6\%, [4]) LGA [67] SA [68] and CHA (0.5-5\% incidence) $[1,4,6,12,21,22,30,34,3$ $5,41,50,69]$. Belilo et al. (2017) however, reported $30.7 \%$ of the 482 patients they studied had the CHA originating from the SMA [19].

The SMA can also give rise to accessory branches or branches normally derived from other abdominal organ sources, such as the liver, stomach, spleen, and pancreas [45]. The most frequent branches observed are dorsal pancreatic artery $(1.8-25 \%)[70,71]$ transverse pancreatic artery [72] and RHA (replaced (aberrant) or accessory). Replaced RHA originating from the SMA varied in incidence from 6.9 to $17 \%$ [53,72]. Aberrant RHAs can arise from the SMA behind the head of the pancreas and be at risk for right lobe devascularization, if not recognized during a Whipple procedure. Accessory RHA as a SMA branch occurred in $0.6-7 \%$ of individuals $[4,53,72]$. The GDA arose from the SMA in two cases studied by Michels (1955), four cases by Huu et al. (1976) and in ten cases of double GDAs where one GDA originated from the CT and the other from the SMA with the SMA branch being dominant $[45,72,73]$. RGEA may also arise from the SMA instead of the GDA [72,74]. Jain and Motwani (2013) found a rare case of an accessory SA and LCA arising together from the SMA as a common stem [39]. Other less frequent SMA branches observed include PHA [75] right anterior hepatic artery [76] CA [77] right renal [78] and middle suprarenal artery [79]. Accessory arteries of the colon that may also originate from the SMA include: an accessory colic artery (49.2\% of 65 cases, [80]) accessory LCA $(8 \%,[45,70])$ LCA and superior rectal arteries [70] and an accessory transverse colic artery [70].

The SMA may also be absent (1.4\%) [1,4,65,81] or doubled [65]. Delannoy (1923) found one SMA dividing into IJAs and the other supplied the ascending and the transverse colon [82]. Pillet et al. (1993) and Milnerowicz et al. (2012) also reported duplicated SMA in their articles, where they named the artery supplying ascending and transverse colon the middle mesenteric artery $[36,83]$.

The variation featured in this article is the presence of the LHA from the CT (a replaced or aberrant LHA) and the RHA from the SMA (a replaced or aberrant RHA). They do not originate from a typical position and have replaced a 'usual' artery branch at that location to be the primary blood supply to the corresponding organ or organ section (i.e. the left and right lobes of the liver) $[19,22,69]$. Knowledge of replaced arteries as variations can be lifesaving for patients with bile duct cancer. These vessels are positioned farther away from the bile duct and may be spared from the cancer, allowing for successful tumor removal [19].

\section{CONCLUSION}

Vascular variations are common in the literature and usually asymptomatic. Detailed knowledge of anatomical variations in the branching pattern of the CT and SMA are of considerable importance in abdominal surgical intervention and disease assessment. Awareness of such variations serves to improve the outcome of oncologic, surgical, radiological interventions by avoiding iatrogenic injury, promoting surgical procedure planning, and proper selection of appropriate treatment options. Such familiarity is equally important for anatomy instructors in the various medical disciplines.

\section{ACKNOWLEDGEMENTS}

We would like to thank the family of our donor for their beneficent contribution. Without their generosity, this article would not have been possible.

\section{DISCLAIMER}

The opinions or assertions contained herein are the private ones of the author/speaker and are not to be construed as official or reflecting the views of the Department of Defense, the Uniformed Services University of the Health Sciences or any other agency of the U.S. Government.

\section{REFERENCES}

1. Nelson TM, Pollak R, Jonasson O, et al. Anatomic Variants of the Celiac, Superior Mesenteric, and Inferior Mesenteric Arteries and Their Clinical Relevance. Clin Anat. 1988;1:75-91. 
2. Michels NA. The hepatic, cystic, and retroduodenal arteries and their relations to the biliary ducts. Ann Surg. 1951;133:503-24.

3. Astik RB, Dave UH. Uncommon branching pattern of the celiac trunk: origin of seven branches. Int J Anat Variat. 2011;4:83-5.

4. Awad AS, Imam AA, Mohamed EA, et al. Anatomical Variations of Celiac Trunk: An Angiographic Study. Med J Cairo Univ. 2017;85:119-26.

5. Ozbulbul NI. CT angiography of the celiac trunk: anatomy, variants and pathologic findings. Diagn Interv Radiol. 2011;17:150-7.

6. Saritha S, Supriya G, Anjankar S, et al. Coeliac trunk variations and a reminder of surgical anatomy. An autopsy series of 40 dissections. Int J Res Med Sci. 2013;1:101-5.

7. Sehgal G, Srivastava AK, Sharma PK, et al. Morphometry of the celiac trunk: a multidetector computed tomographic angiographic study. J Ant Soc India 2013;62:23-7.

8. Tihan D, Babacan S, Ergin T, et al. Absence of the celiac trunk in a rectal cancer patient: case report. Anat. 2016;10:235-8.

9. Agarwal S, Pangtey B, Vasudeva N. Unusual Variation in the Branching Pattern of the Celiac Trunk and its Embryological and Clinical Perspective. J Clin Diagn Res. 2016;10:AD05-AD07.

10. Betal R, Mazumdar S, Mazumdar A. Absence of middle colic artery from the superior mesenteric artery. BLDE Univ J Health Sci. 2016;1:49-51.

11. Covanţev S, Mazuruc N, Belic O. An unusual case of colon vascularization by the inferior mesenteric artery. J Vasc Bras. 2017;16:52-5.

12. De Martino RR. Normal and Variant Mesenteric Anatomy. In: Oderich GS (editor). Mesenteric Vascular Disease: Current Therapy. New York, SSBM. 2015;9-23.

13. Indrajit G, Ansuman R, Pallab B. Variant origin of the middle colic artery from the gastroduodenal artery. Int J Anat Variat. 2013;6:13-7.

14. Vijaykishan B, Sontakke Y. Variant Middle Colic Artery Arising from Inferior Mesenteric Artery. Eur J Pharm Med Res. 2018;5:507-9.

15. Michels NA, Siddharth P, Kornblith PL, et al. The variant blood supply to the descending colon, rectosigmoid and rectum based on 400 dissections. Its importance in regional resections: a review of medical literature. Dis Colon Rectum. 1965;8:251-78.

16. Nayak SB, Sirasanagandla SR, Goerge BM, et al. Unusual origin of left colic artery from the superior mesenteric artery and its course across the left kidney. OA Case Reports. 2014;3:32-4.

17. Ramasamy C, Ramasamy SK. Double Middle Colic Arteries in a Female Cadaver of Asian Origin - A Case Report. Rev Arg de Anat Clin. $2015 ; 7: 118-21$

18. Babu ED, Khrab P. Coeliac Trunk Variations: Review with Proposed New Classification Int J Anat Res. 2013;1:165-70.

19. Belilo MA, Ali IA, Abuelnor MA. Cadaveric Study of Anatomica Variations of Hepatic Artery in Sudanese. Anat Phys Biochem Int. J 2017;3:1-4.

20.Alakkam A, Hill RV, Saggio G. Superior mesenteric origin of the proper hepatic artery: embryological and clinical implications. Surg Radiol Anat. 2016;38:747-50.

21. Brasil IRC, Araujo IF, Lima AALA, et al. Computed tomography angiography study of variations of the celiac trunk and hepatic artery in 100 patients. Radiol Bras. 2018;51:32-6

22. Farghadani M, Momeni M, Hekmatnia A, et al. Anatomical variation of celiac axis, superior mesenteric artery, and hepatic artery: Evaluation with multidetector computer tomography angiography. J Res Med. $2016 ; 21: 125$.

23. Khan RN, Ali M, Sadiq M, et al. Detecting Anatomical Variations of Coeliac Trunk Branching Pattern in the Population of Karachi Using 3D Multidetector Computed Tomographic Angiography (MDCTA). Annals ASH KM \& DC. 2017;22:262-9.
24. Lakshmi VVV, Vasanthi A, Devi GR. Anatomical Variation of the Coeliac Trunk. J Dent Med Sci. 2017;16:50-3.

25. Mahajan A, Tiwari S, Mishra S. A Unique Conglomeration of Variations in the Celiac, Hepatic, and Superior Mesenteric Artery: A ClinicoEmbryological Perspective. Int J Appl Basic Med Res. 2018;8:256-8.

26. Marco-Clement I, Martinez-Barco A, Ahumada N, et al. Anatomical variations of the celiac trunk: cadaveric and radiological study. Surg Radiol Anat. 2016;38:501-10

27. Nayak B S, Kumar N, Guru A, et al. Unusual branching pattern of coeliac trunk - a case report. Int J Anat Variat. 2012;5:134-6.

28. Pinal-Garcia DF, Nuno-Guzman CM, Gonzalez-Gonzalez ME, et al. The Celiac Trunk and Its Anatomical Varations: A Cadaveric Study. J Clin Med Res. 2018;10:321-9.

29. Prakash, Rajini T, Mokhasi V, et al. Coeliac trunk and its branches: anatomical variations and clinical implications. Singapore Med J. 2012;53:329-31.

30.Sureka B, Mittal MK, Mittal A, et al. Variations of celiac axis, common hepatic artery and its branches in 600 patients. Indian J Radiol Imaging. 2013;23:223-33.

31. Thamke S, Rani P. Variant anatomy of common hepatic artery and its branching pattern: acadaveric study with clinical implication. Int J Res Med Sci. 2017;5:3966-70

32. Toro JSC, Prada G, Takeuchi SYR, et al. Prevalence of Anatomical Celiac Trunk Variations Using 3D Angiography Computed Tomography Images in a Reference Hospital. J Clin Exp Res Cardiol. 2017;3:201-8.

33. White RD, Weir-McCall JR, Sullivan CM, et al. The Celiac Axis Revisited Anatomic Variants, Pathologic Features, and Implications for Modern Endovascular Management. Radiographics. 2015;35:879-98.

34. Yadav SP, Sinha RS, Patil T. Study of Variations of Coeliac Trunk in Western Maharashtra Population. Int J Cur Res Rev. 2014;6:31-8.

35. Ye Z, Ye S, Zhou D, et al. A rare variation of celiac trunk and hepatic artery complicating pancreaticoduodenectomy. A case report and literature review. Medicine. 2017;96:48:1-5.

36. Milnerowicz S, Milnerowicz A, Tabola R. A middle mesenteric artery. Surg Radiol Anat. 2012;34:973-5.

37. Karmalkar AS, Patil PS, Pote AJ, et al. Anatomical Variation and Clinical Implications of Celiac Trunk and Superior Mesenteric Arteries. Int J Anat Radiol Surg. 2014;3:7-10.

38. Santos PV, Barbosa ABM, Targino VA, et al. Anatomical Variations of the Celiac Trunk: A Systematic Review. ABCD Arq Bras Cir Dig 2018;31:e1403.

39. Jain P, Motwani R. Morphological Variations of Superior Mesenteric Artery: A Cadaveric Study. Int J Anat Res. 2013;1:83-7.

40. Yang IY, Oraee S, Viejo C, et al. Computed tomography celiac trunk topography relating to celiac plexus block. Reg Anesth Pain Med. $2011 ; 36: 21-5$

41. Caliskan E, Acar T, Ozturk M, et al. Coeliac trunk and common hepatic artery variations in children: an analysis with computer tomography angiography. Folia Morphol. 2018;77:670-6.

42. Hamamalini. Variations in the branching pattern of the celiac trunk and its clinical significance. Anat Cell Biol. 2018;51:143-9.

43. Panagouli E, Venieratos D, Lolis E, Skandalakis P. Variations in the anatomy of the celiac trunk: a systematic review and clinical implications. Ann Anat. 2013;195:501-11.

44. Venieratos D, Panagouli E, Lolis E, et al. A morphometric study of the celiac trunk and review of the literature. Clin Anat. 2013;26:741-50.

45. Sahni D, Aggarwal A, Gupta T, et al. Abdominal aorta - Bergman's Comprehensive Encyclopedia of Human Anatomical Variations. Wiley Blackwell: Hoboken, NJ. 2016;619-81. 
46. Dao SB-A, Boubakar O, Moussa Z, et al. Anatomical Variants of Celiac Trunk in Relation to Its Branching: A Preliminary Sub-Saharian Study. Open J Radiol. 2019;9:151-61.

47. Kao GD, Whittingon R, Coia L. Anatomy of the celiac axis and superior mesenteric artery and its significance in radiation therapy. K Radiol Oncol Biol Phys. 1992;25:131-4.

48. Nayak SB, Patil J, Thangarajan R, et al. Long celiac trunk and its low origin and unusual branches: a case report. OA Case Reports. 2013;2:77.

49. Lipshutz B. A composite study of the coeliac axis artery. Ann Surg. 1917; 65:159-69.

50.Adachi B, Hasebe K, Daigaku KT, et al. The Arterial System of the Japanese. Publisher of the Imperial-Japanese University of Kyoto. 1928;2:18-71.

51. Morita M. Reports and conception of three anomalous cases on the area of the coeliac and the superior mesenteric arteries. Igaku Kenkyu (Acta Med). 1935;9:159-72.

52.Uflacker R. Atlas of vascular anatomy: an angiographic approach. Baltimore: Williams \& Wilkins citied in the $\mathrm{Br}$ J Anat 1997; 83(2010):661-7.

53. Ozsoy M, Zeytunlu M, Kilic M, et al. The results of vascular and biliary variations in Turks liver donors: comparison with others. ISR Surg. 2011;1-9.

54. Manso JC, DiDio LJ. Anatomical variations of the human suprarenal arteries. Ann Anat. 2000;182:483-8.

55. Mahajan A, Paul S, Das S. An anatomical variation in the branching pattern of the coeliac trunk. Arch Med Sci. 2009;5:117-9.

56. Makisalo H, Chaib E, Krokos N, et al. Hepatic arterial variations and liver-related diseases of 100 consecutive donors. Transpl Int. 1993;6:325-9.

57. Raviprasanna KH, Kulkarni AL. Anatomic Variations of Coeliac Trunk and its Clinical Significance: A Case Report. ECCEA. 2018;43-6.

58. Matusz P, Iacob N, Micalus GD, et al. An unusual origin of the celiac trunk and the superior mesenteric artery in the thorax. Clin Anat. 2013;26:975-9.

59. Tsukamoto $\mathrm{N}$. The branches of the abdominal visceral arteries in Japanese. Kaibogaku Zasshi Asshi. 1929;2:780-829.

60. Varma KS, Pamidi N, Vollala VR, et al. Hepato-splenomesenteric trunk: a case report. Rom J Morphol Embryo. 2010;151:401-2.

61. Nonent M, Larroche P, Forlodou P, et al. Celiac bimesenteric trunk: Anatomic and radiologic description: case report. Radiology. 2001;220:489-91.

62. Gwyn DG, Skilton JS. A rare variation of the inferior mesenteric artery in man. Anat Rec. 1966;156:235-8.

63. Osawa T, Feng XY, Sasaki N, et al. Rare case of the inferior mesenteric artery and the common hepatic artery arising from the superior mesenteric artery. Clin Anat. 2004;17:518-21.

64. Maleux G, Vaninbroukx J, Demedts I, et al. Common trunk of superior and inferior mesenteric artery at the level of the fifth lumbar vertebra. J Vasc Interv Radiol. 2010;21:296-8.
65. Power JH. Surgical Anatomy of the Arteries, and Descriptive Anatomy of the Heart by the late Valentine Flood, MD Dublin: Dannin and Co. 1850.

66. Sonneland J, Anson BJ, Beaton LE. Surgical anatomy of the arterial supply to the colon from the superior mesenteric artery based upon a study of 600 specimens. Surg Gynecol Obstet. 1958;106:385-98.

67. Ray CE, Gupta AK, Shenoy SS. Left gastric artery arising from the superior mesenteric artery: case reports. Angiology. 1998;49:1017-22.

68. Pandey SK, Bhattacharya S, Mishra RN, et al. Anatomical variations of the splenic artery and its clinical implications. Clin Anat. 2004;17:497-502.

69. Huang CM, Chen RF, Chen QY, et al. Application Value of a 6-Type Classification System for Common Hepatic Artery Absence During Laparoscopic Radical Resections for Gastric Cancer: A Large-Scale SingleCenter Study. Medicine. 2015;94:1-11.

70. Vandamme JP, Van der Schueren G. Re-evaluation of colic irrigation from the superior mesenteric artery. Acta Anat. 1976;95:578-88.

71. Thomford NR, Chandnani PC, Taba AM, et al. Anatomic characteristics of the pancreatic arteries: radiologic observations and their clinical significance. Am J Surg. 1986;151:690-3.

72. Michels NA. Blood Supply and Anatomy of the Upper Abdominal Organs: With a Descriptive Atlas. Philadelphia: Lippincott. 1955;139-293.

73. Huu N, Tam NT, Minh NK. Gastro-duodenal artery arising from the superior mesenteric artery. Bull Assoc Anat (Nancy). 1976;60:779-86.

74. Sakamoto H, Akita K, Sato T. An anomalous right gastroepiploic artery arising from the superior mesenteric artery. Surg Radiol Anat. 1999;21:283-6.

75. Covey AM, Brody LA, Maluccio MA, et al. Variant hepatic arterial anatomy revisited: digital subtraction angiography performed in 600 patients. Radiology 2002;224:542-7.

76. Chaib E, de Souza YEDM, Maruyama MY, et al. Left Hepatic Artery Arising from the Superior Mesenteric Artery: A Case Study of a Rare Anatomic Variation. The Open Anat J. 2010;2:76-8.

77. Katada Y, Kishino M, Ishihara K, et al. Anomalous arterial supply to the gallbladder from the superior mesenteric artery: angiography and computer tomography findings in two cases. Acta Radiol. 2008;49:987-90.

78. Lacout A, Thariat J, Marcy P. Main right renal artery originating from the superior mesenteric artery. Clin Anat. 2012;25:977-8.

79. Honma S, Kudo M. The middle suprarenal artery arising from the superior mesenteric artery. Surg Radiol Anat. 2012;34:93-5.

80. Koizumi M, Horiguchi M. Accessory arteries supplying the human transverse colon. Acta Ansat (Basel). 1990;137:246-51.

81. Wu Y, Peng W, Wu H, et al. Absence of the superior mesenteric artery in an adult and a new classification method for superior-inferior mesenteric arterial variations. Surg Radiol Anat. 2013;36:511-5.

82. Delannoy E. Artery mesenteric superior double. Bull Mem Soc Anat Paris. 1923;93:346

83. Pillet J, Reigner B, Lhoste P, et al. Arterial vascularization of the colon. The middle mesenteric artery. Bull Assoc Anat (Nancy). 1993;77:27-30. 